\title{
THE ANTI-IMPLANTATION PROPERTY OF INTRALUMINAL FLUID IN RATS WITH AN INTRA-UTERINE SILK THREAD SUTURE
}

\author{
S. K. BATTA AND R. R. GHAUDHURY \\ The Department of Pharmacology, \\ Postgraduate Institute of Medical Education and Research, Chandigarh, India
}

(Received 9th January 1968)

\begin{abstract}
Summary. The intraluminal fluid from the rat uterus with an intrauterine silk thread suture exerts an anti-implantation effect when administered intraluminally into the uterus of a recipient rat on Day 2 and Day 4 but not on Day 6 of pregnancy. It is suggested that the intra-uterine device exerts its antifertility effect by release of a pharmacologically active agent.
\end{abstract}

Batta \& Chaudhury (1968) have demonstrated that an intra-uterine suture in one horn of the rat uterus prevents implantation in the contralateral control horn when a passage is created between the two horns. They suggest that an intra-uterine foreign body in one horn may liberate a substance which passes into the two horns and prevents implantation in the control horn. The studies described below were carried out to test the hypothesis that a foreign body in the rat uterus may be producing a substance which does not allow the fertilized ova to develop.

In these experiments an intra-uterine silk thread suture was placed in twenty adult female rats. The method of inserting the suture has already been described (Chaudhury, 1965; Batta \& Chaudhury, 1968). These rats were allowed to rest for 2 weeks before being used for the experiments. Another group of fertile female rats was mated with known fertile males and the day on which thick clumps of spermatozoa were detected in the vagina was called Day 1 of pregnancy. Laparotomy under ether anaesthesia, was performed on groups of these rats on Days 2, 4 and 6. Both the uterine horns of such recipient rats were exposed.

At the same time as the recipient rat was operated on, a rat with an intrauterine suture in one horn of the uterus at the oestrous phase of the cycle was selected as the donor rat and also subjected to laparotomy under ether anaesthesia. Intraluminal fluid $(0.05 \mathrm{ml})$ was taken out from the horn with the suture by means of a fine number 20 needle and immediately injected into the left horn of the uterus of the recipient rat. The same volume of intraluminal fluid was taken from the uterine horn without the device from the donor rat and administered to the right uterine horn of the recipient rat. The animals were then allowed to recover from the anaesthesia. On Day 10 of pregnancy 
laparotomy was again performed under ether anaesthesia in the recipient rats and the number of implantation sites noted in both uterine horns. The experimental design was such that the intraluminal fluid was administered to eleven rats on Day 4 of pregnancy and to six rats each on Day 2 and Day 6 of pregnancy. The results of these three series of experiments are shown in Table 1 where the mean number of implantation sites in the recipient rats is given.

TABLE 1

RESULTS INDICATING THE NUMBER OF IMPLANTATION SITES IN BOTH UTERINE HORNS OF THE RECIPIENT RAT

\begin{tabular}{c|c|c|c|c|c|c}
\hline & & \multicolumn{2}{|c|}{$\begin{array}{c}\text { No. of implantation } \\
\text { sites }\end{array}$} & \multicolumn{2}{|c|}{$\begin{array}{c}\text { Average no. of } \\
\text { implantation sites }\end{array}$} & P values \\
$\begin{array}{c}\text { Days of pregnancy } \\
\text { of recipient rat }\end{array}$ & $\begin{array}{c}\text { No. of } \\
\text { rats }\end{array}$ & $\begin{array}{c}\text { Fluid injected } \\
\text { from horn with } \\
\text { device }\end{array}$ & $\begin{array}{c}\text { Fluid injected } \\
\text { from control } \\
\text { horn }\end{array}$ & $\begin{array}{c}\text { Fluid injected } \\
\text { from horn with } \\
\text { device }\end{array}$ & $\begin{array}{c}\text { Fluid injected } \\
\text { from control } \\
\text { horn }\end{array}$ & \\
\hline 2 & 6 & 6 & 20 & $1 \cdot 0$ & $3 \cdot 3$ & $<0.01$ \\
4 & 11 & 7 & 35 & 0.6 & 3.1 & $<0.01$ \\
6 & 6 & 21 & 30 & $3 \cdot 5$ & $5 \cdot 0$ & $<0.05$ \\
\hline
\end{tabular}

It can be seen that when the intraluminal fluid was introduced on Day 2 and Day 4 of pregnancy the fluid from the uterine horn with the device had a distinct anti-fertility effect indicated by the smaller number of implantation sites $(P<0.01)$. The statistical analysis was made by means of paired comparisons (Bailey, 1959). When the fluid was administered on Day 6 of pregnancy ( 2 days after implantation had occurred) there was no statistically significant difference in the number of implantation sites.

These results support the hypothesis suggested by Batta \& Chaudhury (1968), and also mentioned earlier by Marston \& Chang (1964) that the intra-uterine device may be exerting its anti-implantation effect by producing a pharmacologically active substance which inhibits implantation. Experiments are being carried out to identify this substance.

\section{REFERENCES}

BaIley, N. T. J. (1959) Statistical methods in biology. English Universities Press, London.

Batra, S. K. \& Chaudhury, R. R. (1968) The antifertility effect of an intra-uterine silk thread suture in rats with a connection between two uterine horns. F. Reprod. Fert. (In press).

Chaudhury, R. R. (1965) Effect of an intrauterine silk thread on the fertility of female rats. Brit. med. F. i, 31 .

Marston, J. H. \& Chang, M. C. (1964) Action of the intrauterine foreign body in the rat and rabbit. Proc. 2nd int. Conf. Intrauterine Contraception, New York, p. 232. 